\title{
ORTHOPAEDIC MANIPULATIVE PHYSIOTHERAPY IN SOUTH AFRICA
}

\section{ASPECTS OF THE CURRENT SITUATION}

\author{
- MS Uys, BSc Physio (Stell), TED (Unisa) \\ Senior Lecturer in Physiotherapy, \\ University of Stellenbosch
}

- I H Diener, BSc in Physio (Stell)

Part-time Lecturer in Pliysiotherapy, University of the Western Cape, and Private Practitioner

\section{PREAMBLE}

Orthopaedic Manipulative Therapy (OMT) provides comprehensive, conservative management of pain and other symptoms of neuro-musculo-articular dysfunction of the spine and extremities ${ }^{1}$. As a specialisation field within physiotherapy, it includes promotive, preventive, curative and rehabilitative aspects of management.

The Orthopaedic Manipulative Therapists' Group (OMTG) is a special interest group of the South African Society of Physiotherapy (SASP). Its Objectives comprise those of the International Federation of Orthopaedic Manipulative Therapists (IFOMT) ${ }^{2}$ of which it is a member organisation, namely: - to encourage improved standards and promote appropriate means of communication and exchange of information in the field of manipulative and other manual therapy skills;

- to encourage scientific research and promote opportunities for the spread of knowledge of new developments in these fields of manipulative and other manual therapy.

In the South African context, it has the additional aim of working towards the promotion of OMT services to the public in all areas of the country as part of the comprehensive service

\section{Abstracl}

To ensure effective patient care, all members of the health team should review professional competency and standards of service provision. A questionnaire was sent to all members of the orthopaedic Manipulative Therapists group (OMTG) to establish their qualification and skills, and the scope of practice of Orthopaedic Manipulative Therapy (OMT) physiotherapists. It included a short self and peer review.

The results of this study urge the NEC of the OMTG to address pertinent issues that were raised: posl-graduate study, international trends, research, dissemination of knowledge, quality assurance, professional image and prophylactic programmes in a primary health care system.

\section{Opsomming}

Om effektiewe pasiëntsorg te verseker, is dit nodig dat alle gesondheidsorg spanlede professionele bevoegdheid en standaard van dienslewering in heroorweging neem. ' $n$ Vraelys is aan al die lede van die OMTG gestuur om kwalifikasies en vermoens van lede, sowel as die omvang van OMTG praktyk te bepaal. 'n Kort self-en makker-evaluering is ingesluit.

Die resultate van die studie verplig die NUK van die OMTG om dringend aandag aan die volgende sake te gee: nagraadse studies, internasionale tendense, navorsing, verspreiding van kennis, kwaliteitsversekering, professionele beeld en voorkomende programme in 'n primêre gesondheidsorg sisteem. that physiotherapists provide. It aims to pursue and maintain the highest ethical standards in the carrying out of OMT and to represent the interests of OMT and OMT physiotherapists in South Africa ${ }^{3}$.

Membership of the OMTG is open to all physiotherapists and is not limited to physiotherapists who have successfully completed the post-basic OMT course (nor any other course). The qualifications, clinical skills, expertise and experience of members vary greatly and as a result, their professional and educational needs are very different.

\section{INTRODUCTION}

Major changes in South African Health Care Policies have taken place over the last few years and have compelled all health care professionals to re-evaluate themselves and the role they are fulfilling in service provision for all the peoples of this country. A change of major importance to physiotherapists was the advent of first contact practitioner status.

Some other meaningful changes were:

- a greater emphasis on primary health care;

- an increasing community awareness of the importance of healthy lifestyle, including strong public support for prevention and promotion programmes in industry and sport, as well as health promotion programmes in children and the over sixties. These changes were also taking place elsewhere ${ }^{4}$

Concurrently with these changes, there has been discussion within the profession itself about quality assurance and the accreditation of physiotherapy practices 5 . All of the above imply that the practising physiotherapist has to supply evidence of his/her competency to the client in providing an acceptable standard of service.

With the objectives of the OMTG in mind, the National Executive Committee of the Group asked the authors to launch a study to determine how the OMTG could better serve its members in this changed (and changing) situation.

As one of the first initiatives in this process, a preliminary study by questionnaire was decided upon to ascertain the following:

- the qualifications of members of the OMTG;

- the categories of conditions treated, the modalities used and the amount of "success" achieved;

- the perception by members of their own competency;

- the opinion of members on the competency of their colleagues and their opinion on the standard of undergraduate and post-qualification training in South Africa;

- the opinion of members on the role of the OMTG in their area and in the country.

The results of this preliminary study would be used to determine further strategies for research and/or implementation.

\section{METHODS}

The study population consisted of all the registered members of the OMTG at that time (September 1994). The branches then in existence were Southern Transvaal (ST), Western Prov- 
ince (WP), Northern Transvaal (NT), Natal (N) and Eastern Province (EP). A self-administered questionnaire was sent to each member to be returned anonymously with only Branch membership indicated. The questionnaire was devised to include both open- and close-ended questions. Close-ended questions had to be answered on an even numbered scale (Likert Scale).

\section{Number of adequately completed questionnaires received}

Of the 708 questionnaires sent out, 249 were adequately completed and returned by January 1995 (see fig. 1). This represented a $35,2 \%$ response by members, which was much less than expected from a specialist group of professionals. However, this number was considered to be an adequate sample size for the purpose of this study, due to the fact that it was representative of all branches and approximately proportionate to the members in each branch (see figure 1).

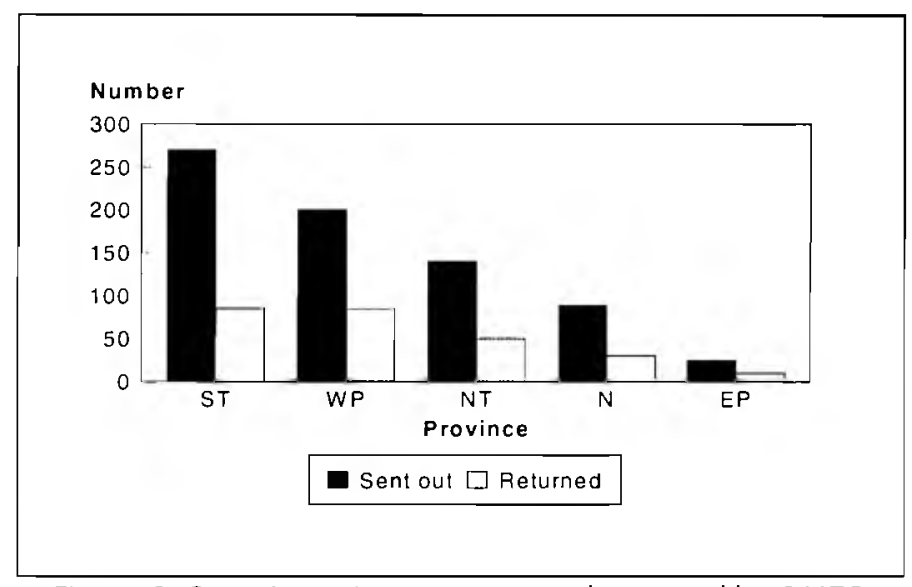

Figure 1. Questionnaires sent out and returned by OMTG therapists

The completed questionnaires were grouped according to area. Answers were then counted and listed under the respective headings. Percentages were determined according to either Branch or National response.

The authors presume that the respondents were members who were particularly interested in voicing their opinion and some bias may be reflected in the results.

It may be of value to repeat this survey and to encourage a better response in order to obtain a true reflection of the real state of affairs in OMT in South A frica. Valuable information was nonetheless obtained, and can be utilised to good effect by the OMTG.

\section{RESULTS AND DISCUSSION}

For easy reading and clarity, the results of the study will be followed directly by the discussion thereof.

\section{Qualification profiles of respondents.}

\section{Qualifications}

Presently, only degree courses in physiotherapy are offered by universities in South Africa. This coincides with the educational principles of the World Confederation of Physical Therapy $^{6}$. Physiotherapists holding a diploma in physiotherapy are thus those who qualified 15 to 20 years ago when diploma courses were still offered. The professional status of degree and diploma graduates are equal in this country.

A major concern is the low percentage of OMT physiotherapists who hold a post graduate degree/diploma. Of the 249 respondents only 29 indicated that they were busy with or had completed post graduate studies, as shown in Table I.
Table I. Qualifications of respondent OMTG therapists

\begin{tabular}{|l|c|c|c|c|}
\hline \multicolumn{1}{|c|}{ Region } & Degree & Diplomo & Total & Post-graduate \\
\hline Southern Transvaal & 63 & 15 & 78 & 9 \\
Western Province & 60 & 18 & 78 & 14 \\
Northern Transvaal & 26 & 22 & 48 & 3 \\
Natal & 23 & 12 & 35 & 3 \\
Eastern Cope & 8 & 2 & 10 & 0 \\
\hline IOTAL & 180 & 69 & 249 & 29 \\
\hline
\end{tabular}

Six different types of post-graduate qualifications were identified from the study results. This also includes an undefined category. The results can be seen in table II.

Table II. Type of post-graduate qualifications held by respondent OMTG therapists

\begin{tabular}{|l|c|}
\hline \multicolumn{1}{|c|}{ Type of degree/diploma } & Number \\
\hline Honours Sports Science & 9 \\
Tertiary Education Diplomo in PT & 11 \\
MSc Orthopoedic PT (completed) & 2 \\
MSc Orthopoedic PT (in process of completion) & 1 \\
MSc Clinical Psychology & 1 \\
Not defined & 5 \\
\hline TOTAL & 29 \\
\hline
\end{tabular}

The OMTG is the largest interest group of the SASP. According to this study, only three respondents had completed or were busy with post-graduate studies in the orthopaedic field, but according to information received from all universities offering higher degrees in orthopaedic physiotherapy, approximately 20 higher degrees were granted in this field up to December 1994. It may be that not all of these graduates belong to the OMTG or have left the country, or did not return their questionnaires.

Of interest is the number (11 out of the 29) of respondents holding Tertiary Education Diplomas.

There are several possible reasons for this paucity of higher degrees, including time and financial constraints for individual physiotherapists aspiring to obtain post-graduates studies $^{7}$. Another reason may be the fact that the financial benefit of having a higher qualification is rare in the public and private sectors. This is true for South Africa as well as elsewhere ${ }^{8}$.

Post-graduate studies and rescarch are perceived as the most important aspects in the process of giving credibility to the physiotherapy profession". The perceived reluctance of SA physiotherapists to become involved in this process is also supported by a previous study ${ }^{4}$.

Internationally, the OMT field is expanding rapidly. "Once regarded as an art, the last decade in particular has witnessed an explosion of basic and applied research into the nature, mechanics, practice and efficacy of manual or manipulative therapy. Clinicians and researchers (in physiotherapy) are evaluating the old as well as developing new clinical approaches"10.

It should be the concern of the OMT Group to investigate this dire shortage of higher trained physiotherapists. However, this will have to be done in collaboration with training universities to find practical solutions to improve the current situation. A specific analysis into type and number of such post-graduate programmes should be done as well as finding ways to make it more accessible for physiotherapists aspiring to further their academic studies. Close liaison between clinicians and researchers is advocated by various authors $4,8,11$ to ensure that physiotherapy is research based, thus providing more effective patient care. Clinicians are also in the ideal 
position to guide researchers towards essential and appropriate research topics.

\section{Continuing Education Courses attended}

Sufficient opportunity for physiotherapists to attend continuing education courses exists in South Africa, and it appears that members of the OMTG make use of this opportunity. The results show that courses are well attended throughout South Africa. This phenomenon can be seen in figure 2 .

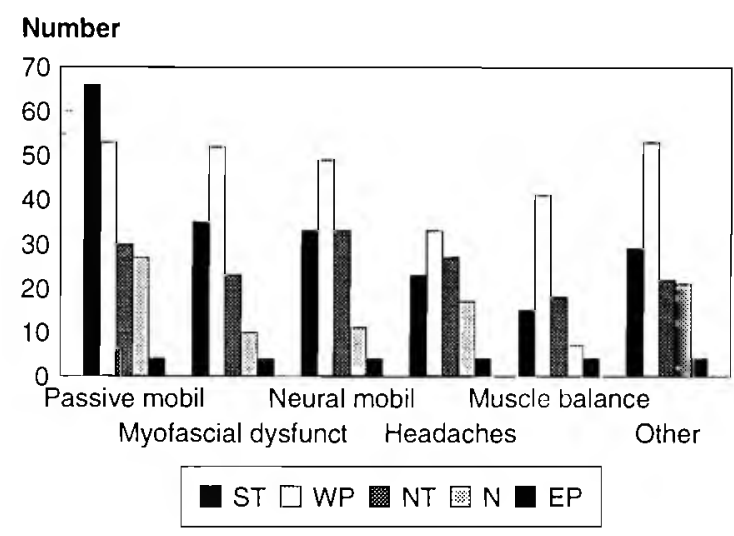

Figure 2. Continuing Education courses attended by OMTG therapists

Much effort goes into the planning of workshops, seminars, two to three day courses and the official, standardised OMT course (112 hours) both at regional and national level.

In this respect the OMTG has served its members well, especially by inviting overseas lectures or giving feedback after international congresses and courses. The members seem to appreciate this service and this is the chosen method of broadening their knowledge base and improving their clinical skills.

Although most respondents were satisfied with the continuing education programmes, members from more isolated areas felt that their specific needs were not met. Most of these courses are presented in the larger cities which makes them difficult and more expensive to attend than for members living near the metropolitan areas.

The concept of integrating different approaches during courses was favoured by $65 \%$ of the respondents. All organising committees country wide should take cognisance of this valuable information.

The authors also feel that courses on clinical decision making should be instituted. Current physiotherapy practice is based on sound clinical decision making processes. "Clinical reasoning provides a safeguard against the risk of having the popular therapy and clinical techniques of the day adopted without question and hence thwarting alternative theories and clinical practice ... Without sound clinical reasoning, clinical practice becomes a technical operation requiring direction from a decision maker" ${ }^{\prime \prime}$. (eg. The referring doctor will prescribe what physiotherapy is needed). Errors in clinical reasoning can occur very easily when there is a lack of knowledge or when the thinking process itself is incorrect.

Undergraduate education and training cannot provide these advanced professional skills and this can only be done at post-graduate (formal or continuing education) level ${ }^{4}$.

From these results it can be seen that the OMTG will be responsible for providing this kind of education to their members because the preferred manner of education is not through formal post-graduate university education.

\section{Information about scope of practice}

\section{Type of conditions treated}

The various types of conditions treated were divided into the seven basic categories of patients most commonly seen at an average practice and can be seen in Table III.

\begin{tabular}{||l|c|c|}
\hline \multicolumn{3}{|c|}{ Table III. Type of conditions treated by respondents } \\
\hline \multicolumn{1}{|c|}{ Type of problem Ireated } & Never/Seldom & Often/Regularly \\
\hline Vertebral problems & $16(6 \%)$ & $233(94 \%)$ \\
Peripheral joinl problems & $55(27 \%)$ & $194(73 \%)$ \\
Sporls injuries & $129(52 \%)$ & $120(48 \%)$ \\
Neural tension problems & $120(48 \%)$ & $129(52 \%)$ \\
Muscle disorders & $125(50 \%)$ & $124(50 \%)$ \\
Rehabilitation & $110(44 \%)$ & $139(56 \%)$ \\
Headaches & $70(28 \%)$ & $179(72 \%)$ \\
\hline
\end{tabular}

Vertebral problems still seem, to form the main category of patients treated by the respondents. This corresponds to situations in various other countries ${ }^{13,14}$. Higher percentages of peripheral joint problems and headaches are also treated.

In contrast with other types of conditions, sports injuries, tension problems and rehabilitation patients are seen less regularly. These results may be a reflection of the distribution of patients seen in an average OMT based practice. To the authors' knowled ge no such figures exist for general practices in South Africa. It may be argued that a greater percentage of the normal population will suffer from vertebral problems as opposed to any other type of problem, including sports injuries.

Physiotherapists in general orthopaedic practices will, therefore treat more patients with vertebral problems than any other type of condition. This tendency seems to be on the increase. In Great Britain the Sickness and Invalid Benefit states that back incapacity has increased by $208,5 \%$ over the last decade ${ }^{15}$.

\section{Referral}

In table IV the results of how patients are being referred to OMTG therapists for treatment is given.

\begin{tabular}{|l|c|c|}
\hline \multicolumn{3}{|c|}{ Table IV. Referral of patients to OMT therapists } \\
\hline \multicolumn{1}{|c|}{ Referred by } & Never/Seldom & Often/Regularly \\
\hline Generol praclitioner & $80(32 \%)$ & $169(68 \%)$ \\
Specialist & $115(46 \%)$ & $134(54 \%)$ \\
First conlacl & $132(53 \%)$ & $117(47 \%)$ \\
Other physiotherapists & $227(91 \%)$ & $22(9 \%)$ \\
Word-of-mouth & $79(32 \%)$ & $170(68 \%)$ \\
\hline \hline
\end{tabular}

A true "professional" is someone who can act autonomously without being prescribed to by another profession. First contact status for physiotherapists (ie not requiring med ical referral, nor compulsory "close collaboration" with a medical practitioner) has been in operation in South Africa since 1994. Although these results showed that most patients were still referred for treatment by a doctor or specialist, a considerable amount of respondents indicated that they were often treating patients on a primary contact basis $(47 \%)$. These figures will, in all probability, increase in the future.

Modalities used

The various treatment modalities used most commonly by OMT physiotherapists were listed and had to be evaluated in terms of frequency of use. The results are shown in Fig 3.

Manual techniques, namely Passive Mobilisation (95\%) and Massage $(91 \%)$, are used extensively and neural mobilisation to a lesser degree $(62 \%)$. This would be an obvious scenario as 


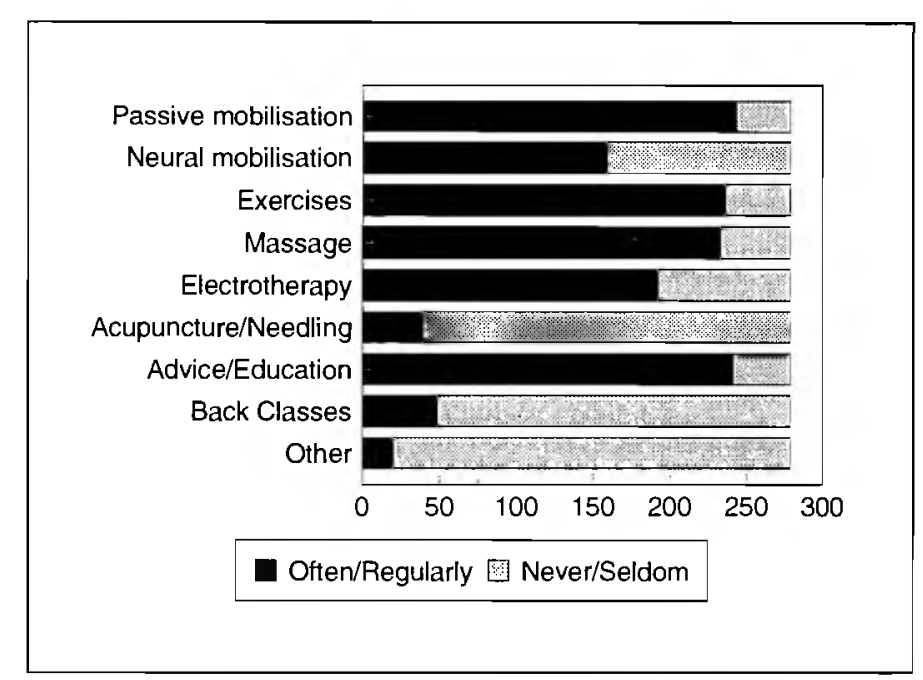

Figure 3. Modalities used during treatment by OMTG therapists

all respondents were manual therapists. The literature is not conclusive, but various authors report that manual therapy may be beneficial in patients with acute and chronic low back pain syndromes ${ }^{16,17}$. If most patients seen by respondents suffer from vertebral problems, then these would be appropriate modalities to be used.

Unfortunately, the questionnaire did not distinguish between mobilisation and manipulation. Both of these would be included under the heading "passive mobilisation". This is seen as a weakness in the questionnaire and valuable information was lost due to this omission.

It is encouraging to note the high percentage of respondents using exercises (92\%) and advice/education (94\%). All patients should be empowered to take responsibility for his/her own health and that can only be achieved through the patient understanding the problem and knowing how to deal with it.

Only $19 \%$ of respondents offer back classes to their patients, or refer patients specifically to a colleague if a back class is appropriate. The main advantage of treating patients in a class setting is the fact that more patients can be seen in a shorter space of time. It is vital that there are enough physiotherapists with skills to provide comprehensive, accessible and equitably distributed services to all patients ${ }^{7}$. It would therefore be logical to conclude that if more physiotherapists offer back classes, more patients would be able to receive some form of physiotherapy service, especially in the South African situation where there is an acute dearth of physiotherapists in many communities.

The high percentage of OMT physiotherapists using Electrotherapy on a regular basis $(75 \%)$ is another reason for concern. Does the present physiotherapy Tariffs System have any bearing on the fact that electrotherapy modalities are so frequently used?

In their Report on Back Pain ${ }^{15}$, the Clinical Standards Advisory Group in the UK states that the following interventions were "proven" valuable treatment strategies:

- manipulation

- active exercise and rehabilitation

- patient education and self-management

- prophylaxis

From the results of this study it is evident that South African OMT physiotherapists do not give adequate attention to the preventive and promotive (ie prophylactic) aspects of neuromusculo-skeletal problems. It seems as if the other proven strategies are well pursued and practised.

\section{Self Assessment}

In this section of the questionnaire close-ended questions were included where respondents had to indicate their choice of answers on a given scale. The questions are given to clarify the response.

View of quality of services rendered

Questions that were included: Are you able to differentiate your patients' problems adequately and to treat patients successfully in 3-6 treatments? Are your patients satisfied with the treatment they receive and how often do they return for the same problem? How often do they refer friends/family to you specifically? How often do you lose patients to other therapists?

Table V. View of quality of service rendered by OMT therapists

\begin{tabular}{|l|c|c|}
\hline \multicolumn{1}{|c|}{ Item } & Never/Seldom & Often/Regularly \\
\hline Ability to differentiate problem & $4(2 \%)$ & $245(98 \%)$ \\
Success with treatment (3-6) & $40(16 \%)$ & $209(84 \%)$ \\
Palienls' satisfaction & $0(0 \%)$ & $249(100 \%)$ \\
Palients return for same problem & $209(84 \%)$ & $40(16 \%)$ \\
"Specially to you" referral & $52(10 \%)$ & $224(90 \%)$ \\
Loss of patients to colleague & $224(98 \%)$ & $5(2 \%)$ \\
\hline
\end{tabular}

From table $\mathrm{V}$ it can be seen that a large percentage of respondents is of the opinion that they provide a high quality of service. More physiotherapists in SA work in private practice than in state service. They rely on patient satisfaction for an adequate turnover of patients. If the quality of service is not good enough, they will soon be out of work.

On the other hand, though, there are as yet no formal quality assurance initiatives or evaluation systems for physiotherapists in operation in South Africa.

What yardsticks were used when these respondents evaluated themselves? Would the public opinion of quality of service correspond with this positive self assessment?

View of own knowledge, skills

Questions: Do you think your knowledge is adequate to assess most patients effectively at first contact? Do you think that you are suitably qualified to treat the problems you are dealing with? Do you refer "difficult" patients to other physiotherapists who are more experienced/have more knowledge than you? Do you think you have made a concerted effort to keep yourself up to date?

The results obtained, as seen in Table VI, correlate well with the high percentage of respondents having attended continuing education courses (Fig2).

\begin{tabular}{|l|c|c||}
\hline \multicolumn{3}{|c|}{ Table VI. View of own knowledge and skills } \\
\hline \multicolumn{1}{|c|}{ Issue } & Poor/Just adequate & More than adequate/Excellent \\
\hline $\begin{array}{l}\text { Own knowledge } \\
\text { Suitably qualified }\end{array}$ & $17(7 \%)$ & \\
& $9(4 \%)$ & \\
\cline { 2 - 4 } & Never/Seldom & Often/Reqularly \\
\hline Referral of patient to other therapist & $187(75 \%)$ & $62(25 \%)$ \\
Consultation of other theropists & $104(42 \%)$ & $145(58 \%)$ \\
Concerted effort to keep updated & $36(14 \%)$ & $213(86 \%)$ \\
\hline
\end{tabular}

Unfortunately, the questionnaire did not distinguish between undergraduate education and acquisition of knowledge/skills after qualifying. No specific information is thus available as to the extent of improved confidence due to the attendance of continuing education courses.

It is encouraging to note some OMT physiotherapists (58\% of respondents) consult their colleagues about difficult pa- 
tients but only $29 \%$ refer their difficult patients to more knowledgeable/experienced physiotherapists.

In the Rules specifying Acts or Omissions which constitute Disgraceful Conduct (Rule 28 of the Code of Conduct for Physiotherapists in South Africa) it is stated clearly that: "The performance, except in an emergency, of professional acts for which the practitioner is inadequately trained and/or insufficiently experienced" could become questionable in terms of misconduct ${ }^{18}$. Are we not therefore ethically bound to refer patients to another physiotherapist if we do not have the knowledge or experience to treat a patient effectively?

Unfortunately, we do not as yet have any specialist OMT physiotherapists registered in South Africa. Even though there is no official register of such "specialists", there are quite a number of very experienced OMT physiotherapists who could be used for this purpose.

\section{Assessment of colleagues and training}

\section{Opinion on peer group}

Questions: Do you think your colleagues examine patients adequately? Do you think most of your colleagues are suitably qualified to treat the patients they see. What do you think of the general standard of OMT practice in SA? What do you think of the standard of undergraduate teaching and post-basic OMT teaching in SA? What do you think of the standard of OMT practice in your area?

The majority of respondents felt that abilities, qualifications and standard of OMT practice of their colleagues were more than adequate (see table VII).

The response to the questions about standards of teaching was very favourable, with $70 \%$ of respondents being of the opinion that the undergraduate and $87 \%$ that the post-basic training is more than adequate or excellent. This should be regarded as a fair to positive response, because OMT is a specialisation area in physiotherapy. The undergraduate programme could only introduce the physiotherapy student to the basic principles of assessment, management and clinical decision making processes in OMT. This implies that the bulk of the clinical knowledge, skill and expertise of OMT physiotherapists should be developed after qualification. This is an area for further investigation, especially as undergraduate curricula in general are currently in the process of being revised to suit the specific health needs of our country.

Respondents' view about the opinion of the users of OMT services

Questions: Have you ever heard physiotherapists/doctors complain about the standard of physiotherapy service in SA? How often do you get patients that come to you for treatment after having been dissatisfied with another physiotherapist's treatment? How often have you had to "rectify" another physiotherapist's bad treatment?

The majority of ratings for all these questions were in the "seldom" category which was defined as "in 25\% of cases

\begin{tabular}{|c|c|c|c|c|}
\hline \multicolumn{5}{|c|}{ Table VII. Opinion on peer group } \\
\hline Issue & Poor & Just adequate & More than adequate & Excellent \\
\hline $\begin{array}{l}\text { Ability of colleagues to examine adequately } \\
\text { Colleagues suitably qualified? } \\
\text { General standard of OMT in South Africa } \\
\text { Slandard of undergraduale teaching in SA } \\
\text { Slandard of post-basic OMT leaching in SA } \\
\text { Standard of OMT in your area: ST (78) } \\
\text { WP (78) } \\
\text { NT (48) } \\
\text { N (35) } \\
\text { EP (10) }\end{array}$ & $\begin{array}{c}9(3.6 \%) \\
6(2.4 \%) \\
13(5.2 \%) \\
12(5 \%) \\
14(6 \%) \\
3(3.9 \%) \\
3(3.8 \%) \\
1(2.1 \%) \\
2(5.7 \%) \\
0(0 \%)\end{array}$ & $\begin{array}{c}64(25.7 \%) \\
47(18.9 \%) \\
42(16.9 \%) \\
64(25 \%) \\
16(7 \%) \\
20(25.6 \%) \\
16(20.5 \%) \\
12(25 \%) \\
10(28.6 \%) \\
4(40 \%)\end{array}$ & $\begin{array}{c}140(56.2 \%) \\
150(60.2 \%) \\
145(58.2 \%) \\
128(52 \%) \\
82(33 \%) \\
39(50 \%) \\
52(66.7 \%) \\
29(60.4 \%) \\
15(42.9 \%) \\
6(60 \%)\end{array}$ & $\begin{array}{c}36(14.5 \%) \\
46(18.5 \%) \\
49(19.7 \%) \\
46(18 \%) \\
137(54 \%) \\
16(20.5 \%) \\
7(9 \%) \\
6(12.5 \%) \\
8(22.8 \%) \\
0(0 \%)\end{array}$ \\
\hline
\end{tabular}

seen". Quite a large percentage of responses were in the "often or regularly" category which constitutes $50 \%$ or more of cases seen. Although these percentages should not be seen as actual numbers, these results show that there may be a significant incidence of complaints, dissatisfied patients and "bad treatment". One would expect that the largest percentage of respondents would answer negatively to this kind of question.

These results should be regarded as a serious matter for concern. The public image of our profession is at stake. More importantly, the standard of service provision is implicated" ... the difference between whether an organisation is mediocre or superb is determined by whether ALL its individual members are mediocre or superb" 4 .

These results do not correlate with the Self Assessment and Peer Review results ${ }^{3,4}$, which is why the authors are of the opinion that immediate action is necessary to ascertain the actual number and type of complaints about OMT services.

\section{General questions}

In this section both open- and close-ended questions were included.

\section{Efforts to keep up (other than courses)}

Questions: Have you ever made use of the OMT library in your area? How often do you read physiotherapy related books/journals? Do you have access to a medical/physiotherapy library?

The main OMTG library is at the Head Office of the OMTG Executive Committee which is currently in Cape Town. There are smaller branch libraries in a few other centres. This means that these facilities are accessible only to those members who live close to such a branch library. Only $10 \%$ of respondents have made use of these libraries while $62 \%$ indicated that they do read physiotherapy related books/journals.

It is not easy to join a university's medical library unless you are an enrolled student or on the academic staff of that university. The vast majority of publications in the OMT field are therefore, not available to the biggest proportion of the OMTG members. The cost of books and other publications is extremely high in SA, which makes it virtually impossible for individual members to afford their own personal libraries. The SA Journal of Physiotherapy which is sent to all members of the SASP and Forum are most probably the only publication that is readily available to some physiotherapists.

\section{OMT Publications}

Questions: Do you think the SASP Journal is adequate re OMT material? Do you think the OMTG should have its own Journal and would you be prepared to pay extra for a more informative newsletter?

The majority of respondents $(57 \%)$ were of the opinion that the SASP Journal published adequate OMT-related articles. This is a general Physiotherapy Journal and some editions concentrate on specific fields. The number of OMT articles published varies and depends entirely on what is received by the Editorial Board.

\section{Writing for a Journal}

Questions: Have you ever considered writing an article in a journal? Have you published an article? Sixty-three percent of respondents indicated that they have considered writing an article, but only $12(4.8 \%)$ have actually published. These were all in local physiotherapy and related journals. There are a number of OMT physiotherapists who have published abroad, 
but obviously their questionnaires were not returned. Reasons given for not writing for publication were numerous and are presented in table VIII.

Table VIII. Reasons given by respondents for not writing for publication

\begin{tabular}{|l|c|}
\hline \multicolumn{1}{|c|}{ Reason } & Number \\
\hline Not enough time & 70 \\
Sees self as incompetent/unqulified & 28 \\
Does not do original research & 9 \\
Not interesled in writing/feels no need for it & 9 \\
Hates wriling & 8 \\
Lacks confidence & 7 \\
Not more skill/knowledge than average physiotheropist & 6 \\
Too lazy/lacks motivalion & 6 \\
Not acodemically inclined & 5 \\
Afraid of criticism fram colleagues & 3 \\
No access to library for literalure search & 2 \\
No mentor available & 1 \\
Works in isolation & 1 \\
Poor journalistic skills & 1 \\
Hates research & 1 \\
Previous bad feedback from Editariol Board & 1 \\
\hline \hline
\end{tabular}

Clinical physiotherapists should not wait for researchers to publish. Development of physiotherapy theory (ie on what we base our practice) is mainly through clinical experience. Clinicians should consider physiotherapy practice as the precursor for research as the results of treatment are as important as the results of empirical research. They should reflect on their treatment outcomes by submitting case studies for publication and thus provide a focus for clinical debate between clinicians, researchers and academics ${ }^{4,10}$.

Exciting new OMT Journals have emerged in the last few years eg. Manual Therapy (1995) and the Journal of Manual and Manipulative Therapy (1993). More and more research is done world wide and this information should become available to OMT members. Substantial benefits to improve patient care are to be gained from these research findings. If current and future physiotherapy practice is research based (ie incorporating research findings into practice), most effective patient care will be provided ${ }^{11}$.

\section{CONCLUSIONS}

Of the results presented a few pertinent issues that need to be addressed as a matter of urgency, became clear.

1. Consultation with the universities needs to take place to increase the availability and accessibility of post-graduate programmes in OMT. Members should be encouraged to further their academic studies and/or become active researchers.

2. Continuing education programmes need to be made accessible and affordable to members in smaller centres. The OMTG should find ways to support the smaller branches, be it in presenting programmes closer to their area or making sponsorship available to these members.

3. Continuing education programmes should include those topics that members are interested in, but international trends and new issues should be included. These courses should provide a forum for improving the members' ability to analyse and compare different strategies, to hypothesise and to make sound clinical decisions based on their clinical reasoning skills.

4. Prophylactic (preventive and promotive aspects of a heal thy lifestyle) and rehabilitation programmes should be boosted by the OMTG.
5. Quality assurance initiatives and other evaluation systems should be instituted in the OMT field to increase clinicians' abilities to improve their practice. This would ensure better patient care.

6. The OMTG should investigate ways of improving the image of OMT physiotherapists in the eyes of patients, doctors and other health care providers.

7. Dissemination of published information and educational material should be addressed as a matter of urgency.

8. Members (especially clinicians) should be encouraged and supported to write for publication in physiotherapy and related journals. The way to start this process may be through encouraging case studies.

9. A positive research climate should be created by this Group through all its undertakings.

The OMTG members are satisfied with the Group and what it has given them through the years, especially with regard to courses offered. To maintain this trust and to be relevant in the current health care system, the Group has to adapt to the changing needs of its members, as well as the changing arena of OMT, both nationally and internationally. Valuable information was obtained through this survey. However, this would have been a worthless exercise followed by a dynamic and timeous response from the National and local executive committees of the OMTG.

\section{Acknowledgement}

The authors wish to thank all the OMTG members who gave up their time to complete this questionnaire. Your further comments and any other suggestions are invited to help us in planning a better future for OMT practice in South Africa.

\section{REFERENCES}

1. IFOMT Educational Standards Document (1992): Adopted in Vail, Colorado.

2. JFOMT Constitution (1996): Adopted in Lillehammer, Norway.

3. OMTG Constitution and Bye Laws (1995): Physiotherapy Publications, Parkview.

4. Grant R. The pursuit of excellence in the face of constant change. Phlysiotherapy 1995;81(6):338-344.

5. Singleton M C. Independent Practice - On the Horns of a Dilemma. Physical Therapy 1987;67(1):54-57.

6. WCPT Declaration of Principle: Education for Entry-level Physical Therapists. Article 14.1 R95/2 (1995): Adopted in Washington.

7. Titchen A. Continuing Education: A study of Physiotherapists' Attitudes. Physiotherapy 1987 a;73(3):121-124.

8. Henderson C. Why pursue a higher degree? P/hysiotherapy 1995;41(2):7981.

9. Irwin-Carruthers S H. An Investigation into post-graduate education in South Africa. SA Jnl of Pluysiotherapy 1991;47(1):3-7.

10. Moore A, Jull G. Editorial. Mannul Throly 1995;1(1):1.

11. CSP Research Development Group. Physiotherapy Resea rch and Continuing Professional Development. Mhysiothripy 1996;82(1):58-62.

12. Jones M. Clinical Reasoning and Pain. Mammal Therapy 1995;1(1):17-24.

13. Grieve G P. Common Vertebnl Joint Problens. Churchill Livingstone Edinburgh 1981:77-81.

14. Callaghan M J. Evaluation of a Back Rehabilitation Group for Chronic Low Back Pain in an Out-patient setting. P/y/siofherapy 1994;80(10)667681

15. Thomson A. Back Pain - The Growing Epidemic. Physiothorapy 1995;81(2):59-60.

16. US Department of Health and Human Services. Acute low back pain problems in Adults. Clinical Practice Guidelines no 14. HCPR publication, USA.

17. Van der Valk R W A, Dekker J, van Baar M E. Physical Theropy for patients with back pain. Mysioflicrapy 1995;81(6):345-351.

18. Department of Health. Rules specifying the Acts or Omissions in respect of which disciplinary steps may be taken by a Professional Board and the Council. Govermment Gazette No. R 137y of 12 August 1994; Government Printers, Pretoria. 